MS16-P4 Temperature dependence of local structure change in lithium peroxide.Yoshitaka Matsushita, ${ }^{a}$ Koichi Monma, ${ }^{a, b}$ FujioIzumi, ${ }^{a}$ Yoshimi Kubo, ${ }^{a}$ Yoshio Katsuya, ${ }^{c}$ Masahiko Tanaka, ${ }^{\mathrm{a}}$ and OsamiSakata, ${ }^{\mathrm{a} a}$ National Institute of Materials Science, Japan, ${ }^{b}$ National Museum of Nature and Science, Japan, 'SPring-8 Service, Co., Japan

\section{E-mail: MATSUSHITA.Yoshitaka@nims.go.jp}

Recently, on environmental issues / energy situation, material development related to next generation energy source with low environmental load type is important and essential issues than ever before. One of the possible energy sources for mobileusage in next generation is lithium secondary (rechargeable) batteries (lithium-air battery). If we can use the $\mathrm{Li}_{-} \mathrm{O}_{2}$ system for new batteries, the expectedspecific energy density $(>5,000 \mathrm{Wh} / \mathrm{kg}$ )is much higher thanthem in current systems. The simple and classic compound $\mathrm{Li}_{2} \mathrm{O}_{2}$ is one of the key materials to develop the newer system.In newly developing batteries, $\mathrm{Li}_{2} \mathrm{O}_{2}$ is crystallized on cathodematerial under $2 \mathrm{Li}+\mathrm{O}_{2}$ reversible reactionduring charging and discharging process. This crystallization leads to cathode clogging phenomena and then result in lowering of output. [1] Therefore, to well-understand $\mathrm{Li}_{2} \mathrm{O}_{2}$ properties including crystallography is very essential and important for developing new battery with controlled stable output. However, surprisingly even now, the crystal structure of simple and classic compound $\mathrm{Li}_{2} \mathrm{O}_{2}$ is still unknown: two crystal structure models are proposed only. [2] In this study, to identify the crystal structure of $\mathrm{Li}_{2} \mathrm{O}_{2}$ and its local structure change, we had carried out powder synchrotron x-ray diffraction measurements from around $85 \mathrm{~K}$ to $300 \mathrm{~K}$, using angular high-resolution powder diffractometer installed at the BL15XU, SPring-8.All process for sample preparation werecarried out under dry $\mathrm{Ar}$ atmosphere: the sample was ground well and packed into a Lindenmannglass capillary of $0.3 \mathrm{~mm}$ diameter, after then the capillary was sealed. From this study, we concluded that the crystal structure of $\mathrm{Li}_{2} \mathrm{O}_{2}$ takes one of the previously proposed models $\left(\mathrm{Pb}_{3} / \mathrm{mmc}\right)$ [2], and the compound does not show any phase transitions in the temperature range. The details will be presented.

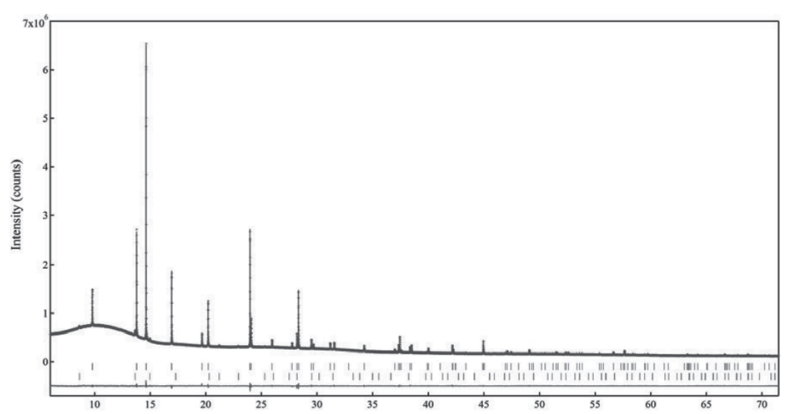

Figure 1.Powder synchrotron $\mathrm{x}$-ray diffraction pattern at room temperature.

[1] Kumar, B., Kumar, J., Leese, R., Fellner, J. P., Rodrigues, S. J.,\&Abrahamc, K. M. (2010).J. Electrochem.Soc.157, A50 A54, and references within.

[2] Cota, L. G.\& de la Mora, P. (2005). ActaCryst.B61, 133 136.
MS16-P5 Phase transitions in $\mathrm{KIO}_{3}$. Lkhamsuren Bayarjargal $^{\mathrm{a}}$, Leonore Wiehl ${ }^{\mathrm{a}}$, Alexandra Friedrich ${ }^{\mathrm{a}}$, Björn Winkler $^{\mathrm{a}}$, Erick A. Juarez-Arellano ${ }^{\mathrm{b}}$, Wolfgang Morgenroth ${ }^{\mathrm{a}}$, Eiken Haussühl ${ }^{\mathrm{a}}$, ${ }^{a}$ Institut für Geowissenschaften, Universität Frankfurt am Main, Germany, ${ }^{b}$ Universidad del Papaloapan, Mexico

E-mail: L.Wiehl@kristall.uni-frankfurt.de

The high-pressure behavior of $\mathrm{KIO}_{3}$ was studied up to 30 $\mathrm{GPa}$ using single-crystal and powder X-ray diffraction, Raman spectroscopy, second harmonic generation (SHG) experiments and density functional-theory (DFT) based calculations. Triclinic $\mathrm{KIO}_{3}$ shows two pressure-induced structural phase transitions at $7 \mathrm{GPa}$ and at $14 \mathrm{GPa}$. Single crystal X-ray diffraction at $8.7 \mathrm{GPa}$ has been employed to solve the structure of the first high-pressure phase (space group $R 3, a=5.89(1) \AA$, á $\left.=62.4(1)^{\circ}\right)$. The bulk modulus, $B$, of this phase has been obtained by fitting a 2nd order Birch-Munaghan equation of state (eos) to synchrotron X-ray powder diffraction data resulting in $B_{\text {exp,2nd }}=67(3) \mathrm{GPa}$ and $B^{\prime}=4$ (fixed). The DFT model gave $B_{\mathrm{DFT}, 2 \mathrm{nd}}=70.9 \mathrm{GPa}$, and, for a 3rd order Birch-Munaghan eos $B_{\mathrm{DFT}, 3 \mathrm{rd}}=67.9 \mathrm{GPa}$ with a pressure derivative of $B{ }_{\mathrm{DFT}, 3 \mathrm{rd}}=5.9$. Both high-pressure transformations are detectable by Raman spectroscopy and the observation of SHG signals [1]. The presence of strong SHG signals shows that all high pressure phases are acentric. By using different pressure media we have shown that the transition pressures are very strongly influenced by shear stresses. Earlier work on low- and high-temperature transitions is complemented by low-temperature heat capacity measurements. We find no evidence for the presence of an orientational glass, in contrast to earlier dielectric studies, but consistent with earlier low-temperature diffraction studies. This presentation will focus on the structural relationships between the high pressure phase and the ambient-pressure phases at low [2], ambient $[3,4,5]$ and high $[3,6]$ temperatures.

Acknowledgement: The authors thank S. Haussühl, J. Wang and M. Lü for supplying $\mathrm{KIO}_{3}$ single crystals, and J. Biehler and F. Schröder for assistance in powder X-ray diffraction measurements. We thank HASYLAB/DESY, Germany, for synchrotron beamtime and financial support. We thank the Advanced Light Source, USA, for beamtime and the staff at beamline 12.2.2 for help with the synchrotron facilities. Financial support from the Deutsche Forschungsgemeinschaft, Germany, within SPP1236 (Projects Ba4020, Wi1232, Fr2491), the BMBF (Project 05K10RFA) and the FOKUS program of the Goethe University is gratefully acknowledged.

[1] Bayarjargal, L., Winkler, B., Friedrich, A., Biehler, J., Schröder, F. \& Juarez-Arellano, E.A. (2010). Acta Cryst. A66, s203, 26th European Crystallography Meeting, Darmstadt, Germany.

[2] Lucas, B.W. (1985). Acta Cryst. C41, 1388-1391.

[3] Hamid, S.A. (1973). Z. Kristallogr. 137, 412-421.

[4] Kalinin, V.P., Ilykhin, V.V. \& Belov, N.V. (1978). Doklady Akademii Nauk SSSR 239, 590-593.

[5] Lucas, B.W. (1984). Acta Cryst. C40, 1989-1992.

[6] Byrom, P. G. \& Lucas, B.W. (1987). Acta Cryst. C43, 1649-1651.

\section{Keywords: high pressure; crystal structures; phase} transitions

Keywords: Crystal structure; Lithium peroxide; Synchrotron powder diffraction 